\title{
PERAMALAN SUKU BUNGA ACUAN (BI-7 DAY REPO RATE) DENGAN METODE FUZZY TIME SERIES
}

\author{
N. R. Purwanti ${ }^{1}$, S. Musdalifah², dan Andri ${ }^{3}$ \\ 1,2,3 Program Studi Matematika Jurusan Matematika FMIPA Universitas Tadulako \\ Jalan Soekarno-Hatta Km. 09 Tondo, Palu 94118, Indonesia. \\ 1nindirestianapurwanti@gmail.com, 2selvymusdalifah@gmail.com, 3andri90@gmail.com.
}

\section{ABSTRACT}

The BI-7 Day Repo Rate is a policy interest rate that reflects the monetary policy stance or stance set by Bank Indonesia and announced to the public. The BI 7-Day Repo Rate greatly affects many economic sectors, which in turn can affect the level or rate of inflation. Economic actors pay close attention to the BI-7 Day Repo Rate set by the Board of Governors. If the policy interest rate set by the Board of Governors is not in accordance with the trend of economic conditions at a certain time, it will have a negative impact on Indonesia's economic conditions. This is why it is important to forecast the BI-7 Day Repo Rate in the hope that economic actors can anticipate the long-term impact of the determination of the BI-7 Day Repo Rate. The method used in this study is a fuzzy time series with the best model of order 15 with an accuracy calculated using MAPE of $1.14636957 \%$. The fuzzy time series method works by capturing patterns from historical data and then using it to project future data. The results of this study indicate that the movement of the Reference Interest Rate from December 2020 - December 2021 is in the range of $4.25 \%-4.52 \%$.

Keywords : BI-7 Day Repo Rate, Fuzzy Time Series, MAPE, Forecasting.

\section{ABSTRAK}

BI-7 Day Repo Rate merupakan suku bunga kebijakan yang mencerminkan sikap atau stance kebijakan moneter yang ditetapkan oleh Bank Indonesia dan diumumkan kepada publik. BI 7-Day Repo Rate sangat mempengaruhi banyak sektor ekonomi, yang pada akhirnya dapat mempengruhi tingkat atau laju inflansi. Para pelaku ekonomi sangat memperhatikan BI-7 Day Repo Rate yang ditetapkan oleh Dewan Gubernur. Apabila suku bunga kebijakan yang ditetapkan oleh Dewan Gubernur tidak sesuai dengan tren kondisi ekonomi diwaktu tertentu maka akan berdampak negatif kepada kondisi ekonomi Indonesia. Hal inilah yang menyebabkan pentingya dilakukan peramalan BI7 Day Repo Rate dengan harapan para pelaku ekonomi dapat mengantisipasi dampak jangka 
panjang dari penetapan BI-7 Day Repo Rate ini. Metode yang digunakan dalam penelitian ini adalah fuzzy time series dengan model terbaik orde 15 dengan tingkat akurasi yang dihitung menggunakan MAPE sebesar 1,14636957\%. Metode fuzzy time series bekerja dengan menangkap pola dari data historis kemudian digunakan untuk memproyeksikan data yang akan datang. Hasil penelitian ini menunjukkan bahwa pergerakan tingkat Suku Bunga Acuan dari bulan Desember 2020 - Desember 2021 adalah rentang 4,25\% - 4,52\%.

Kata Kunci : BI-7 Day Repo Rate, Fuzzy Time Series, MAPE, Peramalan.

\section{PENDAHULUAN}

Suku bunga Bank Indonesia adalah suku bunga kebijakan yang ditetapkan oleh Bank Indonesia dan diumukan kepada publik. Salah satu faktor yang menyebabkan suku bunga BI naik dan turun adalah tingkat inflansi. Bank Indonesia akan menaikkan tingkat suku bunga apabila inflansi kedepan diperkirakan melampaui sasaran yang telah ditetapkan, dan akan menurunkan tingkat suku bunga jika inflansi kedepan diperkirakan berada dibawah sasaran (Anggraeini, 2015).

Menurut Paramasatya dkk (2017) Nilai jual produk sangat dipengaruhi oleh kebijakan moneter yang ditetapkan oleh Bank Indonesia. Bank Indonesia memiliki tujuan untuk mencapai dan memelihara kestabilan nilai rupiah, tujuan ini tercantum dalam UU N0. 3 Tahun 2004 Pasal 7 tentang Bank Indonesia. Hal yang dimaksud dengan kestabilan nilai rupiah antara lain adalah kestabilan terhadap harga-harga barang dan jasa yang tercermin pada inflansi. Secara operasional, stance kebijakan moneter dicerminkan oleh suku bunga kebijakan yang dalam implementasinya mampu mempengaruhi suku bunga pasar uang, suku bunga deposito, suku bunga kredit perbankan, sektor perdagangan dan bisnis, perusahaan sekuritas, serta pasar modal. BI-7 Day Repo Rate dapat mempengaruhi banyak sektor ekonomi, pada akhirnya BI-7 Day Repo Rate dapat mempengruhi tingkat atau laju inflansi.

Para pelaku ekonomi sangat memperhatikan BI-7 Day Repo Rate yang ditetapkan oleh Dewan Gubernur. Apabila suku bunga kebijakan yang ditetapkan oleh Dewan Gubernur tidak sesuai dengan tren kondisi ekonomi diwaktu tertentu maka akan berdampak negatif kepada kondisi ekonomi Indonesia (Paramasatya dkk, 2017). Hal ini yang menyebabkan pentingnya peramalan BI-7 Day Repo Rate dengan harapan para pelaku bisnis dapat mengantispasi dampak jangka panjang dari penetapan BI-7 Day Repo Rate.

\section{METODE PENELITIAN}

Lokasi pengolahan data dilakukan di Laboratorium Komputer Jurusan Matematika Fakultas Matematika dan IImu Pengetahuan Alam, Universitas Tadulako. Sumber data yang digunakan merupakan data sekunder yaitu yaitu data yang diperoleh dari website resmi Bank Indonesia https://www.bi.go.id/id/bi-7day-rr/default.aspx. Adapun jenis data yang dalam penelitian ini adalah data kuantitatif yaitu data suku bunga acuan BI-7 Day Repo Rate dalam kurun waktu 4 tahun 8 bulan. 
Penelitian ini dilakukan dengan tahap Menentukan panjang interval data Suku Bunga Acuan (BI-7 Day Repo Rate) menggunakan aturan sturgess yaitu dengan cara menghitung banyak kelas $(k)$ dan panjang kelas $(l)$ kemudian Melakukan pengolahan data Suku Bunga Acuan (BI-7 Day Repo Rate) menggunakan metode fuzzy time series untuk memperoleh hasil peramalan Suku Bunga Acuan (BI-7 Day Repo Rate) pada bula Desember 2020 - Desember 2021, dengan cara menentukan himpunan semesta pembicaraan, mendefinisikan himpunan fuzzy, fuzifikasi data, menetukan relasi logika fuzzy, defuzifikasi dan memperoleh hasil peramalan selanjutnya Menguji tingkat akurasi hasil peramalan menggunakan MAPE.

\section{HASIL DAN PEMBAHASAN}

\subsection{Hasil}

Peramalan Suku Bunga Acuan (BI-7 Day Repo Rate) pada penelitian kali ini menggunakan data dari bulan April 2016 sampai November 2020 data tersebut diperoleh dari website resmi Bank Indonesia yang ditunjukkan dalam Tabel 1.

Tabel 1 : Data Suku Bunga Acuan (BI 7-Day Repo Rate)

\begin{tabular}{|c|l|c|c|c|c|c|}
\hline \multirow{2}{*}{ No. } & \multirow{2}{*}{ Bulan } & \multicolumn{5}{|c|}{ Tahun } \\
\cline { 3 - 7 } & & 2016 & 2017 & 2018 & 2019 & 2020 \\
\hline 1 & Januari & - & 4.75 & 4.25 & 6.00 & 5.00 \\
\hline 2 & Februari & - & 4.75 & 4.25 & 6.00 & 4.75 \\
\hline 3 & Maret & - & 4.75 & 4.25 & 6.00 & 4.50 \\
\hline 4 & April & 5.50 & 4.75 & 4.25 & 6.00 & 4.50 \\
\hline 5 & Mei & 5.50 & 4.75 & 4.75 & 6.00 & 4.50 \\
\hline 6 & Juni & 5.25 & 4.75 & 5.25 & 6.00 & 4.25 \\
\hline 7 & Juli & 5.25 & 4.75 & 5.25 & 5.75 & 4.00 \\
\hline 8 & Agustus & 5.25 & 4.50 & 5.50 & 5.50 & 4.00 \\
\hline 9 & September & 5.00 & 4.25 & 5.75 & 5.25 & 4.00 \\
\hline 10 & Oktober & 4.75 & 4.25 & 5.75 & 5.00 & 4.00 \\
\hline 11 & November & 4.75 & 4.25 & 6.00 & 5.00 & 4.00 \\
\hline 12 & Desember & $4.75 \%$ & 4.25 & 6.00 & 5.00 & - \\
\hline
\end{tabular}

Sumber : https://www.bi.go.id/id/bi-7day-rr/default.aspx

\subsubsection{Penerapan Metode Sturgess dan Fuzzy Time Series}

Langkah 1. Mendefinisikan Himpunan Semesta

Untuk mendefinisikan himpunan semesta digunakan formula sebagai berikut :

$$
U=\left[D_{\text {min }}, D_{\text {max }}\right]
$$

Dimana $U$ merupakan himpunan semesta, $D_{\min }$ merupakan nilai terkecil dari data historis $D_{\max }$ merupakan nilai terbesar dari data historis. 
Berdasarkan data pada tabel 1 diperoleh himpunan semesta sebagai berikut :

$$
\begin{gathered}
U=\left[D_{\min }, D_{\max }\right] \\
U=[3,75,6,00]
\end{gathered}
$$

Langkah 2. Membagi $U$ menjadi beberapa inteval.

Untuk membagi interval terlebih dahulu akan dihitung banyak kelas $(k)$ dan panjang kelas (l) menggunakan metode sturgess sebagai berikut :

$k=1+3,322 \log (n)$

$k=1+3,322 \log (56)$

$k=6,070188027 \approx 7$

Untuk panjang kelas $(l)$ dihitung menggunakan rumus sebagai berikut:

$l=\frac{D_{\max }-D_{\min }}{k}$

$l=\frac{6,00-3,75}{6,070188027}$

$l=0,37$

Selanjutnya diperoleh interval seperti Tabel 2.

Tabel 2 : Interval dan Titik Tengah Rataan

\begin{tabular}{|l|c|c|}
\hline No & Interval $\left(u_{i}\right)$ & Titik Tengah $\left(m_{i}\right)$ \\
\hline 1 & $u_{1}=[3,75 ; 4,12)$ & $m_{1}=3,93$ \\
\hline 2 & $u_{2}=[4,12 ; 4,49)$ & $m_{2}=4,30$ \\
\hline 3 & $u_{3}=[4,49 ; 4,86)$ & $m_{3}=4,67$ \\
\hline 4 & $u_{4}=[4,86 ; 5,23)$ & $m_{4}=5,04$ \\
\hline 5 & $u_{5}=[5,23 ; 5,60)$ & $m_{5}=5,41$ \\
\hline 6 & $u_{6}=[5,60 ; 5,97)$ & $m_{6}=5,78$ \\
\hline 7 & $u_{7}=[5,97 ; 6,34)$ & $m_{6}=6,15$ \\
\hline
\end{tabular}

Langkah 3. Mendefinisikan Himpunan Fuzzy

Mendefinisikan himpunan fuzzy pada semesta $U$ yang nilai linguistiknya didasarkan pada interval partisi $u_{i}$ Maka diperoleh himpunan fuzzy yang terbentuk adalah sebagai berikut :

$$
\begin{aligned}
& A_{1}=\left\{\frac{1}{u_{1}}+\frac{0,5}{u_{2}}+\frac{0}{u_{3}}+\frac{0}{u_{4}}+\frac{0}{u_{5}}+\frac{0}{u_{6}}+\frac{0}{u_{7}}\right\} \\
& A_{2}=\left\{\frac{0,5}{u_{1}}+\frac{1}{u_{2}}+\frac{0,5}{u_{3}}+\frac{0}{u_{4}}+\frac{0}{u_{5}}+\frac{0}{u_{6}}+\frac{0}{u_{7}}\right\} \\
& A_{3}=\left\{\frac{0}{u_{1}}+\frac{0,5}{u_{2}}+\frac{1}{u_{3}}+\frac{0,5}{u_{4}}+\frac{0}{u_{5}}+\frac{0}{u_{6}}+\frac{0}{u_{7}}\right\} \\
& A_{4}=\left\{\frac{0}{u_{1}}+\frac{0}{u_{2}}+\frac{0,5}{u_{3}}+\frac{1}{u_{4}}+\frac{0,5}{u_{5}}+\frac{0}{u_{6}}+\frac{0}{u_{7}}\right\} \\
& A_{5}=\left\{\frac{0}{u_{1}}+\frac{0}{u_{2}}+\frac{0}{u_{3}}+\frac{0,5}{u_{4}}+\frac{1}{u_{5}}+\frac{0,5}{u_{6}}+\frac{0}{u_{7}}\right\} \\
& A_{6}=\left\{\frac{0}{u_{1}}+\frac{0}{u_{2}}+\frac{0}{u_{3}}+\frac{0}{u_{4}}+\frac{0,5}{u_{5}}+\frac{1}{u_{6}}+\frac{0,5}{u_{7}}\right\} \\
& A_{7}=\left\{\frac{0}{u_{1}}+\frac{0}{u_{2}}+\frac{0}{u_{3}}+\frac{0}{u_{4}}+\frac{0}{u_{5}}+\frac{0,5}{u_{6}}+\frac{1}{u_{7}}\right\}
\end{aligned}
$$


Langkah 4. Fuzzifikasi Data Historis

Berdasarkan himpunan fuzzy yang telah terbentuk pada langkah sebelumnya, maka diperoleh fuzzy linguistic $A_{i}=u_{i}$ yang memiliki derajat keanggotaan tertinggi yaitu 1 , disajikan dalam Tabel 3.

Tabel 3 : Fuzzy Set Terhadap Interval

\begin{tabular}{|c|c|c|}
\hline No. & Interval & Fuzzy Set \\
\hline 1 & $u_{1}$ & $A_{1}$ \\
\hline 2 & $u_{2}$ & $A_{2}$ \\
\hline 3 & $u_{3}$ & $A_{3}$ \\
\hline 4 & $u_{4}$ & $A_{4}$ \\
\hline 5 & $u_{5}$ & $A_{5}$ \\
\hline 6 & $u_{6}$ & $A_{6}$ \\
\hline 7 & $u_{7}$ & $A_{7}$ \\
\hline
\end{tabular}

Tabel 4 : Fuzzifikasi Data Historis

\begin{tabular}{|c|c|c|c|}
\hline No & Periode & BI-7 Day Repo Rate & Fuzzifikasi \\
\hline 1 & April 2016 & 5,50 & $A_{5}$ \\
\hline 2 & Mei 2016 & 5,50 & $A_{5}$ \\
\hline 3 & Juni 2016 & 5,25 & $A_{5}$ \\
\hline 4 & Juli 2016 & 5,25 & $A_{5}$ \\
\hline 5 & Agustus 2016 & 5,25 & $A_{5}$ \\
\hline$\vdots$ & $\vdots$ & $\vdots$ & $\vdots$ \\
\hline 55 & Oktober 2020 & 4,00 & $A_{1}$ \\
\hline 56 & November 2020 & 3,75 & $A_{1}$ \\
\hline
\end{tabular}

3.1.2. Penerapan Fuzzy Time Series Orde 1, 2, 7 dan 15 dalam Meramalkan Suku Bunga Acuan (BI-7 Day Repo Rate)

1. Membentuk Relasi Logika Fuzzy (FLR) Membuat fuzzy logic relationship orde 1, orde 2 , orde 7 , dan orde 15 berdasarkan formula berikut :

$F(t-n), \ldots, F(t-2), F(t-1) \rightarrow F(t)$ 
Tabel 5 : Relasi Logika Fuzzyorde 1, orde 2, orde 7, dan orde 15

\begin{tabular}{|c|c|c|c|c|}
\hline No. & Periode & FLR Orde 1 & FLR Orde 2 & FLR Orde 7 \\
\hline 1. & Apr-16 & - & - & - \\
\hline 2. & Mei-16 & $A_{5} \rightarrow A_{5}$ & - & - \\
\hline 3. & Jun-16 & $A_{5} \rightarrow A_{5}$ & $A_{5}, A_{5} \rightarrow A_{5}$ & - \\
\hline 4. & Jul-16 & $A_{5} \rightarrow A_{5}$ & $A_{5}, A_{5} \rightarrow A_{5}$ & - \\
\hline 5. & Agu-16 & $A_{5} \rightarrow A_{5}$ & $A_{5}, A_{5} \rightarrow A_{5}$ & - \\
\hline 6. & Sep-16 & $A_{5} \rightarrow A_{4}$ & $A_{5}, A_{5} \rightarrow A_{4}$ & - \\
\hline$\vdots$ & $\vdots$ & $\vdots$ & $\vdots$ & $\vdots$ \\
\hline 39 & Jun-19 & $A_{7} \rightarrow A_{7}$ & $A_{7}, A_{7} \rightarrow A_{7}$ & $A_{7}, A_{7}, A_{7}, A_{7}, A_{7}, A_{7}, A_{7}$ \\
$\rightarrow A_{7}$
\end{tabular}

2. Membentuk Grub Relasi Logika Fuzzy yaitu dengan cara mengelompokkan Relasi Logika Fuzzy yang memiliki sisi kiri yang sama.

Tabel 6 : Grub Relasi Logika Fuzzy orde 1, orde 2, orde 7, dan orde 15

\begin{tabular}{|c|c|c|}
\hline No. & FLRG Orde 1 & FLRG Orde 2 \\
\hline 1. & $A_{2} \rightarrow A_{2}, A_{2}, A_{2}, A_{2}, A_{2}, A_{2}, A_{2}, A_{3}$ & $\begin{array}{l}A_{2}, A_{2} \\
\rightarrow A_{2}, A_{2}, A_{2}, A_{2}, A_{2}, A_{2}, A_{3}\end{array}$ \\
\hline 2. & $\begin{array}{l}A_{3} \\
\rightarrow A_{2}, A_{3}, A_{3}, A_{3}, A_{3}, A_{3}, A_{3}, A_{3}, A_{3}, A_{3}, A_{3}, A_{5}\end{array}$ & $A_{2}, A_{3} \rightarrow A_{5}$ \\
\hline 3. & $A_{4} \rightarrow A_{3}$ & $A_{3}, A_{2} \rightarrow A_{2}$ \\
\hline 4. & $\vdots$ & $\vdots$ \\
\hline 5. & - & $A_{6}, A_{7} \rightarrow A_{7}$ \\
\hline 6. & - & $\begin{array}{l}A_{7}, A_{7} \\
\rightarrow A_{6}, A_{7}, A_{7}, A_{7}, A_{7}, A_{7}, A_{7}, A_{7}\end{array}$ \\
\hline
\end{tabular}

3. Defuzzyfikasi

Selanjutnya dilkukan proses defuzzifikasi atau proses perhitungan untuk mengembalikan bentuk fuzzy (kabur) pada bentuk crips (tegas), keluaran dari proses ini yaitu suatu peramalan dengan prinsip sebagai berikut:

a. $\operatorname{FLRG}\left(A_{i} \rightarrow \emptyset\right), \hat{F}(t)=m_{i}$

b. $\quad \operatorname{FLRG}\left(A_{i} \rightarrow A_{j}\right), \widehat{F}(t)=m_{j}$

$\operatorname{FLRG}\left(A_{i} \rightarrow A_{j}, \ldots, A_{k}\right), \hat{F}(t)=\frac{a m_{j}+\cdots+b m_{k}}{a+\cdots+b}$ 
Tabel 7 : Hasil perhitungan peramalan pada data training

\begin{tabular}{|c|c|c|c|c|c|c|}
\hline No. & Periode & $\begin{array}{c}\text { Data } \\
\text { Aktual }\end{array}$ & $\begin{array}{c}\text { Peramalan } \\
\text { Orde 1 }\end{array}$ & $\begin{array}{c}\text { Peramalan } \\
\text { Orde 2 }\end{array}$ & $\begin{array}{c}\text { Peramalan } \\
\text { Orde 7 }\end{array}$ & $\begin{array}{c}\text { Peramalan } \\
\text { Orde 15 }\end{array}$ \\
\hline 1. & Apr-16 & 5,50 & - & - & - & - \\
\hline 2. & Mei-16 & 5,50 & 5,41 & - & - & - \\
\hline 3. & Jun-16 & 5,25 & 5,41 & 5,41 & - & - \\
\hline 4. & Jul-16 & 5,25 & 5,41 & 5,41 & - & - \\
\hline 5. & Agu-16 & 5,25 & 5,41 & 5,41 & - & - \\
\hline$\vdots$ & $\vdots$ & $\vdots$ & $\vdots$ & $\vdots$ & $\vdots$ & $\vdots$ \\
\hline 39. & Jun-19 & 6,00 & 6,10 & 6,10 & 5,96 & 6,15 \\
\hline $40 .$. & Jul-19 & 5,75 & 6,10 & 6,10 & 5,96 & 5,78 \\
\hline
\end{tabular}

\subsubsection{Perhitungan Tingkat Akurasi Metode Fuzzy Time Series}

Nilai MAPE untuk metode fuzzy time diperoleh dengan perhitungan sebagai berikut :

$$
\text { MAPE }=\frac{1}{n} \sum_{t=1}^{n}\left|\frac{x_{t}-f(t)}{x_{t}}\right| \times 100 \%
$$

Dengan $x_{t}$ adalah nilai data historis pada masing-masing periode dan $f(t)$ adalah nilai hasil peramalan pada masing-masing periode.

Tabel 8 : Perbandingan tingkat akurasi metode fuzzy logic relationship

\begin{tabular}{|c|c|c|}
\hline No. & Metode & MAPE \\
\hline 1. & Fuzzy Time Series orde 1 & $2,79426460 \%$ \\
\hline 2. & Fuzzy Time Series orde 2 & $2,75335551 \%$ \\
\hline 3. & Fuzzy Time Series orde 7 & $1,80339291 \%$ \\
\hline 4. & Fuzzy Time Series orde 15 & $1,14636957 \%$ \\
\hline
\end{tabular}

\subsubsection{Perhitungan peramalan data Testing}

Perhitungan peramalan harga emas pada data testing dalam membentuk Relasi Logika Fuzzy, hasil fuzzifikasidata 15 periode sebelumnya direlasikan dengan $\emptyset$ karena dalam perhitungan ini seolah-olah penulis tidak mengetahui suku bunga acuan waktu $t$ seperti yang disajikan dalam Tabel 9 .

Tabel 9 : Relasi Logika Fuzzy dan Grub Relasi Logika Fuzzy Data Testing

\begin{tabular}{|c|c|c|c|}
\hline No & Bulan & FLR & FLRG \\
\hline 1 & Agu-19 & $\begin{array}{c}A_{3}, A_{5}, A_{5}, A_{5}, A_{6}, A_{6}, A_{7}, A_{7}, A_{7}, A_{7}, A \\
A_{7}, A_{7}, A_{7}, A_{6} \rightarrow \emptyset\end{array}$ & $A_{3}, A_{5}, A_{5}, A_{5}, A_{6}, A_{6}, A_{7}, A_{7}, A_{7}, A_{7}, A_{7}$, \\
\hline 2 & Sep-19 & $\begin{array}{c}A_{5}, A_{5}, A_{5}, A_{6}, A_{6}, A_{7}, A_{7}, A_{7}, A_{7}, A_{7}, A \\
A_{7}, A_{7}, A_{6}, A_{5} \rightarrow \emptyset\end{array}$ & $\begin{array}{c}A_{5}, A_{5}, A_{5}, A_{6}, A_{6}, A_{7}, A_{6} \rightarrow A_{7}, A_{7}, A_{7}, A_{7}, A_{7}, \\
A_{7}, A_{7}, A_{6}, A_{5} \rightarrow \emptyset\end{array}$ \\
\hline 3 & Okt-19 & $\begin{array}{c}A_{5}, A_{5}, A_{6}, A_{6}, A_{6}, A_{7}, A_{7}, A_{7}, A_{7}, A_{7}, A \\
A_{7}, A_{6}, A_{5}, A_{5} \rightarrow \emptyset\end{array}$ & $\begin{array}{c}A_{5}, A_{5}, A_{6}, A_{6}, A_{6}, A_{7}, A_{7}, A_{7}, A_{7}, A_{7}, A_{7}, \\
A_{7}, A_{6}, A_{5}, A_{5} \rightarrow \emptyset\end{array}$ \\
\hline
\end{tabular}




\begin{tabular}{|c|c|c|c|}
\hline 4 & Nov-19 & $\begin{array}{c}A_{5}, A_{6}, A_{6}, A_{6}, A_{7}, A_{7}, A_{7}, A_{7}, A_{7}, A_{7}, A \\
A_{6}, A_{5}, A_{5}, A_{4} \rightarrow \emptyset\end{array}$ & $\begin{array}{c}A_{5}, A_{6}, A_{6}, A_{6}, A_{7}, A_{7}, A_{7}, A_{7}, A_{7}, A_{7}, A_{7}, \\
A_{6}, A_{5}, A_{5}, A_{4} \rightarrow \emptyset\end{array}$ \\
\hline 5 & Des-19 & $\begin{array}{c}A_{6}, A_{6}, A_{7}, A_{7}, A_{7}, A_{7}, A_{7}, A_{7}, A_{7}, A_{7}, A \\
A_{5}, A_{5}, A_{4}, A_{4} \rightarrow \emptyset\end{array}$ & $\begin{array}{c}A_{6}, A_{6}, A_{7}, A_{7}, A_{7}, A_{7}, A_{7}, A_{7}, A_{7}, A_{7}, A_{6}, \\
A_{5}, A_{5}, A_{4}, A_{4} \rightarrow \emptyset\end{array}$ \\
\hline 6 & Jan-20 & $\begin{array}{c}A_{6}, A_{7}, A_{7}, A_{7}, A_{7}, A_{7}, A_{7}, A_{7}, A_{7}, A_{6}, A \\
A_{5}, A_{4}, A_{4}, A_{4} \rightarrow \emptyset\end{array}$ & $\begin{array}{c}A_{6}, A_{7}, A_{7}, A_{7}, A_{7}, A_{7}, A_{7}, A_{7}, A_{7}, A_{6}, A_{5}, \\
A_{5}, A_{4}, A_{4}, A_{4} \rightarrow \emptyset\end{array}$ \\
\hline 7 & Feb-20 & $\begin{array}{c}A_{7}, A_{7}, A_{7}, A_{7}, A_{7}, A_{7}, A_{7}, A_{7}, A_{6}, A_{5}, A \\
A_{4}, A_{4}, A_{4}, A_{4} \rightarrow \emptyset\end{array}$ & $\begin{array}{c}A_{7}, A_{7}, A_{7}, A_{7}, A_{7}, A_{7}, A_{7}, A_{7}, A_{6}, A_{5}, A_{5}, \\
A_{4}, A_{4}, A_{4}, A_{4} \rightarrow \emptyset\end{array}$ \\
\hline 8 & Mar-20 & $\begin{array}{c}A_{7}, A_{7}, A_{7}, A_{7}, A_{7}, A_{7}, A_{7}, A_{6}, A_{5}, A_{5}, A \\
A_{4}, A_{4}, A_{4}, A_{3} \rightarrow \emptyset\end{array}$ & $\begin{array}{c}A_{7}, A_{7}, A_{7}, A_{7}, A_{7}, A_{7}, A_{7}, A_{6}, A_{5}, A_{5}, A_{4}, \\
A_{4}, A_{4}, A_{4}, A_{3} \rightarrow \emptyset \\
\end{array}$ \\
\hline 9 & Apr-20 & $\begin{array}{c}A_{7}, A_{7}, A_{7}, A_{7}, A_{7}, A_{7}, A_{6}, A_{5}, A_{5}, A_{4}, A \\
A_{4}, A_{4}, A_{3}, A_{3} \rightarrow \emptyset \\
\end{array}$ & $\begin{array}{c}A_{7}, A_{7}, A_{7}, A_{7}, A_{7}, A_{7}, A_{6}, A_{5}, A_{5}, A_{4}, A_{4}, \\
A_{4}, A_{4}, A_{3}, A_{3} \rightarrow \emptyset \\
\end{array}$ \\
\hline 10 & Mei-20 & $\begin{array}{c}A_{7}, A_{7}, A_{7}, A_{7}, A_{7}, A_{6}, A_{5}, A_{5}, A_{4}, A_{4}, A \\
A_{4}, A_{3}, A_{3}, A_{3} \rightarrow \emptyset\end{array}$ & $\begin{array}{c}A_{7}, A_{7}, A_{7}, A_{7}, A_{7}, A_{6}, A_{5}, A_{5}, A_{4}, A_{4}, A_{4}, \\
A_{4}, A_{3}, A_{3}, A_{3} \rightarrow \emptyset \\
\end{array}$ \\
\hline 11 & Jun-20 & $\begin{array}{c}A_{7}, A_{7}, A_{7}, A_{7}, A_{6}, A_{5}, A_{5}, A_{4}, A_{4}, A_{4}, A \\
A_{3}, A_{3}, A_{3}, A_{3} \rightarrow \emptyset \\
\end{array}$ & $\begin{array}{c}A_{7}, A_{7}, A_{7}, A_{7}, A_{6}, A_{5}, A_{5}, A_{4}, A_{4}, A_{4}, A_{4}, \\
A_{3}, A_{3}, A_{3}, A_{3} \rightarrow \emptyset \\
\end{array}$ \\
\hline 12 & Jul-20 & $\begin{array}{c}A_{7}, A_{7}, A_{7}, A_{6}, A_{5}, A_{5}, A_{4}, A_{4}, A_{4}, A_{4}, A \\
A_{3}, A_{3}, A_{3}, A_{2} \rightarrow \emptyset\end{array}$ & $\begin{array}{c}A_{7}, A_{7}, A_{7}, A_{6}, A_{5}, A_{5}, A_{4}, A_{4}, A_{4}, A_{4}, A_{3}, \\
A_{3}, A_{3}, A_{3}, A_{2} \rightarrow \emptyset\end{array}$ \\
\hline 13 & Agu-20 & $\begin{array}{c}A_{7}, A_{7}, A_{6}, A_{5}, A_{5}, A_{4}, A_{4}, A_{4}, A_{4}, A_{3}, A \\
A_{3}, A_{3}, A_{2}, A_{1} \rightarrow \emptyset\end{array}$ & $\begin{array}{c}A_{7}, A_{7}, A_{6}, A_{5}, A_{5}, A_{4}, A_{4}, A_{4}, A_{4}, A_{3}, A_{3} \\
A_{3}, A_{3}, A_{2}, A_{1} \rightarrow \emptyset\end{array}$ \\
\hline 14 & Sep-20 & $\begin{array}{c}A_{7}, A_{6}, A_{5}, A_{5}, A_{4}, A_{4}, A_{4}, A_{4}, A_{3}, A_{3}, A \\
A_{3}, A_{2}, A_{1}, A_{1} \rightarrow \emptyset\end{array}$ & $\begin{array}{c}A_{7}, A_{6}, A_{5}, A_{5}, A_{4}, A_{4}, A_{4}, A_{4}, A_{3}, A_{3}, A_{3} \\
A_{3}, A_{2}, A_{1}, A_{1} \rightarrow \emptyset\end{array}$ \\
\hline 15 & Okt-20 & $\begin{array}{c}A_{6}, A_{5}, A_{5}, A_{4}, A_{4}, A_{4}, A_{4}, A_{3}, A_{3}, A_{3}, A \\
A_{2}, A_{1}, A_{1}, A_{1} \rightarrow \emptyset\end{array}$ & $\begin{array}{c}A_{6}, A_{5}, A_{5}, A_{4}, A_{4}, A_{4}, A_{4}, A_{3}, A_{3}, A_{3}, A_{3}, \\
A_{2}, A_{1}, A_{1}, A_{1} \rightarrow \emptyset \\
\end{array}$ \\
\hline 16 & Nov-20 & $\begin{array}{c}A_{5}, A_{5}, A_{4}, A_{4}, A_{4}, A_{4}, A_{3}, A_{3}, A_{3}, A_{3}, A \\
A_{1}, A_{1}, A_{1}, A_{1} \rightarrow \emptyset\end{array}$ & $\begin{array}{c}A_{5}, A_{5}, A_{4}, A_{4}, A_{4}, A_{4}, A_{3}, A_{3}, A_{3}, A_{3}, A_{2} \\
A_{1}, A_{1}, A_{1}, A_{1} \rightarrow \emptyset\end{array}$ \\
\hline
\end{tabular}

Berdasarkan Grub Relasi Logika Fuzzy yang telah terbentuk kemudian dilakukan perhitungan peramalan dengan prinsip sebagai berikut :

1. $\operatorname{FLRG}\left(A_{a}, \ldots, A_{o} \rightarrow \emptyset\right), \hat{F}(t)=\frac{m_{a}+\cdots+m_{o}}{15}$

2. FLRG $\left(A_{a}, \ldots, A_{o} \rightarrow A_{j}\right), \widehat{F}(t)=m_{j}$

3. FLRG $\left(A_{a}, \ldots, A_{o} \rightarrow A_{j}, \ldots, A_{k}\right), \hat{F}(t)=\frac{a m_{j}+\cdots+b m_{k}}{a+\cdots+b}$

Tabel 10 : Hasil Peramalan Data Testing

\begin{tabular}{|c|c|c|c|}
\hline No. & Bulan & Data Aktual & Data Peramalan \\
\hline 1 & Agustus 2019 & 5,00 & 5,82 \\
\hline 2 & September 2019 & 5,25 & 5,87 \\
\hline 3 & Oktober 2019 & 5,00 & 5,87 \\
\hline 4 & November 2019 & 5,00 & 5,85 \\
\hline 5 & Desember 2019 & 5,00 & 5,82 \\
\hline 6 & Januari 2020 & 5,00 & 5,78 \\
\hline 7 & Februari 2020 & 4,75 & 5,73 \\
\hline 8 & Maret 2020 & 4,50 & 5,63 \\
\hline 9 & April 2020 & 4,50 & 5,53 \\
\hline 10 & Mei 2020 & 4,50 & 5,43 \\
\hline 11 & Juni 2020 & 4,25 & 5,33 \\
\hline 12 & Juli 2020 & 4,00 & 5,21 \\
\hline 13 & Agustus 2020 & 4,00 & 5,06 \\
\hline
\end{tabular}




\begin{tabular}{|c|c|c|c|}
\hline 14 & September 2020 & 4,00 & 4,91 \\
\hline 15 & Oktober 2020 & 4,00 & 4,76 \\
\hline 16 & November 2020 & 3,75 & 4,64 \\
\hline
\end{tabular}

\subsubsection{Perhitungan Peramalan Suku Bunga Acuan (BI-7 Day Repo Rate)}

Perhitungan peramalan Suku Bunga Acuan (BI-7 Day Repo Rate) pada bulan Desember 2020 sampai Desember 2021 mengunkan metode fuzzy time series orde 15 yang memiliki nilai MAPE sebesar 1,14636957\%. Proses perhitungan peramalan dimulai dengan pembentukan FLR dan FLRG, sebagaimana yang disajikan dalam Tabel 11.

Tabel 11 : Relasi Logika Fuzzy dan Grub Relasi Logika Fuzzy

\begin{tabular}{|c|c|c|c|}
\hline No & Bulan & FLR & FLRG \\
\hline 1 & $\begin{array}{l}\text { Desember } \\
2020\end{array}$ & $\begin{array}{c}A_{5}, A_{4}, A_{4}, A_{4}, A_{3}, A_{3}, A_{3}, A_{3}, A_{3}, A_{2}, A_{1}, \\
A_{1}, A_{1}, A_{1}, A_{1} \rightarrow \emptyset\end{array}$ & $\begin{array}{c}A_{5}, A_{4}, A_{4}, A_{4}, A_{3}, A_{3}, A_{3}, A_{3}, A_{3}, A_{2}, A_{1}, \\
A_{1}, A_{1}, A_{1}, A_{1} \rightarrow \emptyset\end{array}$ \\
\hline 2 & $\begin{array}{c}\text { Januari } \\
2021\end{array}$ & $\begin{array}{c}A_{4}, A_{4}, A_{4}, A_{3}, A_{3}, A_{3}, A_{3}, A_{3}, A_{3}, A_{2}, A_{1}, \\
A_{1}, A_{1}, A_{1}, A_{3} \rightarrow \emptyset\end{array}$ & $\begin{array}{c}A_{4}, A_{4}, A_{4}, A_{3}, A_{3}, A_{3}, A_{3}, A_{3}, A_{3}, A_{2}, A_{1}, \\
A_{1}, A_{1}, A_{1}, A_{3} \rightarrow \emptyset\end{array}$ \\
\hline 3 & $\begin{array}{l}\text { Februari } \\
2021\end{array}$ & $\begin{array}{c}A_{4}, A_{4}, A_{3}, A_{3}, A_{3}, A_{3}, A_{3}, A_{2}, A_{1}, A_{1}, A_{1} \\
A_{1}, A_{1}, A_{3}, A_{2} \rightarrow \emptyset\end{array}$ & $\begin{array}{c}A_{4}, A_{4}, A_{3}, A_{3}, A_{3}, A_{3}, A_{3}, A_{2}, A_{1}, A_{1}, A_{1}, \\
A_{1}, A_{1}, A_{3}, A_{2} \rightarrow \emptyset\end{array}$ \\
\hline 4 & Maret 2021 & $\begin{array}{c}A_{4}, A_{3}, A_{3}, A_{3}, A_{3}, A_{3}, A_{2}, A_{1}, A_{1}, A_{1}, A_{1}, \\
A_{1}, A_{3}, A_{2}, A_{2} \rightarrow \emptyset\end{array}$ & $\begin{array}{c}A_{4}, A_{3}, A_{3}, A_{3}, A_{3}, A_{3}, A_{2}, A_{1}, A_{1}, A_{1}, A_{1}, \\
A_{1}, A_{3}, A_{2}, A_{2} \rightarrow \emptyset\end{array}$ \\
\hline 5 & April 2021 & $\begin{array}{c}A_{3}, A_{3}, A_{3}, A_{3}, A_{3}, A_{2}, A_{1}, A_{1}, A_{1}, A_{1}, A_{1} \\
A_{3}, A_{2}, A_{2}, A_{2} \rightarrow \emptyset\end{array}$ & $\begin{array}{c}A_{3}, A_{3}, A_{3}, A_{3}, A_{3}, A_{2}, A_{1}, A_{1}, A_{1}, A_{1}, A_{1}, \\
A_{3}, A_{2}, A_{2}, A_{2} \rightarrow \emptyset\end{array}$ \\
\hline 6 & Mei 2021 & $\begin{array}{c}A_{3}, A_{3}, A_{3}, A_{3}, A_{2}, A_{1}, A_{1}, A_{1}, A_{1}, A_{1}, A_{3}, \\
A_{2}, A_{2}, A_{2}, A_{2} \rightarrow \emptyset\end{array}$ & $\begin{array}{c}A_{3}, A_{3}, A_{3}, A_{3}, A_{2}, A_{1}, A_{1}, A_{1}, A_{1}, A_{1}, A_{3}, \\
A_{2}, A_{2}, A_{2}, A_{2} \rightarrow \emptyset \\
\end{array}$ \\
\hline 7 & Juni 2021 & $\begin{array}{c}A_{3}, A_{3}, A_{3}, A_{2}, A_{1}, A_{1}, A_{1}, A_{1}, A_{1}, A_{3}, A_{2} \\
A_{2}, A_{2}, A_{2}, A_{2} \rightarrow \emptyset \\
\end{array}$ & $\begin{array}{c}A_{3}, A_{3}, A_{3}, A_{2}, A_{1}, A_{1}, A_{1}, A_{1}, A_{1}, A_{3}, A_{2}, \\
A_{2}, A_{2}, A_{2}, A_{2} \rightarrow \emptyset\end{array}$ \\
\hline 8 & Juli 2021 & $\begin{array}{c}A_{3}, A_{3}, A_{2}, A_{1}, A_{1}, A_{1}, A_{1}, A_{1}, A_{3}, A_{2}, A_{2} \\
A_{2}, A_{2}, A_{2}, A_{2} \rightarrow \emptyset\end{array}$ & $\begin{array}{c}A_{3}, A_{3}, A_{2}, A_{1}, A_{1}, A_{1}, A_{1}, A_{1}, A_{3}, A_{2}, A_{2}, \\
A_{2}, A_{2}, A_{2}, A_{2} \rightarrow \emptyset\end{array}$ \\
\hline 9 & $\begin{array}{l}\text { Agustus } \\
2021\end{array}$ & $\begin{array}{c}A_{3}, A_{2}, A_{1}, A_{1}, A_{1}, A_{1}, A_{1}, A_{3}, A_{2}, A_{2}, A_{2} \\
A_{2}, A_{2}, A_{2}, A_{2} \rightarrow \emptyset\end{array}$ & $\begin{array}{c}A_{3}, A_{2}, A_{1}, A_{1}, A_{1}, A_{1}, A_{1}, A_{3}, A_{2}, A_{2}, A_{2}, \\
A_{2}, A_{2}, A_{2}, A_{2} \rightarrow \emptyset\end{array}$ \\
\hline 10 & $\begin{array}{c}\text { September } \\
2021 \\
\end{array}$ & $\begin{array}{c}A_{2}, A_{1}, A_{1}, A_{1}, A_{1}, A_{1}, A_{3}, A_{2}, A_{2}, A_{2}, A_{2} \\
A_{2}, A_{2}, A_{2}, A_{2} \rightarrow \emptyset\end{array}$ & $\begin{array}{c}A_{2}, A_{1}, A_{1}, A_{1}, A_{1}, A_{1}, A_{3}, A_{2}, A_{2}, A_{2}, A_{2}, \\
A_{2}, A_{2}, A_{2}, A_{2} \rightarrow \emptyset\end{array}$ \\
\hline 11 & $\begin{array}{c}\text { Oktober } \\
2021\end{array}$ & $\begin{array}{c}A_{1}, A_{1}, A_{1}, A_{1}, A_{1}, A_{3}, A_{2}, A_{2}, A_{2}, A_{2}, A_{2} \\
A_{2}, A_{2}, A_{2}, A_{2} \rightarrow \emptyset\end{array}$ & $\begin{array}{c}A_{1}, A_{1}, A_{1}, A_{1}, A_{1}, A_{3}, A_{2}, A_{2}, A_{2}, A_{2}, A_{2}, \\
A_{2}, A_{2}, A_{2}, A_{2} \rightarrow \emptyset\end{array}$ \\
\hline 12 & $\begin{array}{l}\text { November } \\
2021\end{array}$ & $\begin{array}{c}A_{1}, A_{1}, A_{1}, A_{1}, A_{3}, A_{2}, A_{2}, A_{2}, A_{2}, A_{2}, A_{2} \\
A_{2}, A_{2}, A_{2}, A_{2} \rightarrow \emptyset\end{array}$ & $\begin{array}{c}A_{1}, A_{1}, A_{1}, A_{1}, A_{3}, A_{2}, A_{2}, A_{2}, A_{2}, A_{2}, A_{2}, \\
A_{2}, A_{2}, A_{2}, A_{2} \rightarrow \emptyset\end{array}$ \\
\hline 13 & $\begin{array}{l}\text { Desember } \\
2021\end{array}$ & $\begin{array}{c}A_{1}, A_{1}, A_{1}, A_{3}, A_{2}, A_{2}, A_{2}, A_{2}, A_{2}, A_{2}, A_{2} \\
A_{2}, A_{2}, A_{2}, A_{2} \rightarrow \emptyset\end{array}$ & $\begin{array}{c}A_{1}, A_{1}, A_{1}, A_{3}, A_{2}, A_{2}, A_{2}, A_{2}, A_{2}, A_{2}, A_{2}, \\
A_{2}, A_{2}, A_{2}, A_{2} \rightarrow \emptyset\end{array}$ \\
\hline
\end{tabular}


Berdasarkan Grub Relasi Logika Fuzzy yang telah terbentuk kemudian dilakukan perhitungan peramalan dengan prinsip sebagai berikut :

1. $\operatorname{FLRG}\left(A_{a}, \ldots, A_{o} \rightarrow \emptyset\right), \hat{F}(t)=\frac{m_{a}+\cdots+m_{o}}{15}$

2. FLRG $\left(A_{a}, \ldots, A_{o} \rightarrow A_{j}\right), \widehat{F}(t)=m_{j}$

3. $\operatorname{FLRG}\left(A_{a}, \ldots, A_{o} \rightarrow A_{j}, \ldots, A_{k}\right), \hat{F}(t)=\frac{a m_{j}+\cdots+b m_{k}}{a+\cdots+b}$

Tabel 12: Hasil Perhitungan Peramalan

\begin{tabular}{|c|c|c|}
\hline No. & Periode & Peramalan \\
\hline 1 & Desember 2020 & 4,52 \\
\hline 2 & Januari 2021 & 4,47 \\
\hline 3 & Februari 2021 & 4,42 \\
\hline 4 & Maret 2021 & 4,37 \\
\hline 5 & April 2021 & 4,32 \\
\hline 6 & Mei 2021 & 4,30 \\
\hline 7 & Juni 2021 & 4,27 \\
\hline 8 & Juli 2021 & 4,25 \\
\hline 9 & Agustus 2021 & 4,22 \\
\hline 10 & September 2021 & 4,20 \\
\hline 11 & Oktober 2021 & 4,20 \\
\hline 12 & November 2021 & 4,22 \\
\hline 13 & Desember 2021 & 4,25 \\
\hline
\end{tabular}

\subsection{Pembahasan}

Dalam penelitian ini perhitungan menggunakan metode fuzzy time seriesi dimulai dari model fuzzy time series orde 1 sampai dengan orde 15. Namun dikarenakan nilai MAPE pada masing-masing orde terus menurun makan digunakan model fuzzy time series orde 15 untuk melakukan peramalan dimana model fuzzy time series orde 15 sudah memiliki tingkat akurasi sangat baik yaitu $1,14636957 \%$ dan juga dapat meramalkan 17 periode.

Selanjutnya perhitungan peramalan data testing pada bulan Agustus 2019 - November 2020 menggunakan metode fuzzy time series orde 15, kemudian diperoleh hasil peramalan yang tidak jauh berbeda dengan data aktual. Hal ini menunjukkan bahwa metode fuzzy time series orde 15 merupakan metode terbaik untuk melakukan peramalan Suku Bunga Acuan (BI7 Day Repo Rate) pada bulan Desember 2020 - Desember 2021.

Hasil peramalan Suku Bunga Acuan (BI-7 Day Repo Rate) mengalami peningkatan dari bulan sebelumnya dimana pada bulan November 2020 Tingkat Suku Bunga Acuan (BI-7 Day Repo Rate ) 3,75\% sedangkan pada bulan Desember 2020 Tingkat Suku Bunga Acuan (BI-7 Day Repo Rate) $4,52 \%$. 
Tabel 13 : hasil perhitungn peramalan Suku Bunga Acuan (BI-7 Day Repo Rate)

\begin{tabular}{|c|c|c|}
\hline No. & Periode & Peramalan \\
\hline 1 & Desember 2020 & 4,52 \\
\hline 2 & Januari 2021 & 4,47 \\
\hline 3 & Februari 2021 & 4,42 \\
\hline 4 & Maret 2021 & 4,37 \\
\hline 5 & April 2021 & 4,32 \\
\hline 6 & Mei 2021 & 4,30 \\
\hline 7 & Juni 2021 & 4,27 \\
\hline 8 & Juli 2021 & 4,25 \\
\hline 9 & Agustus 2021 & 4,22 \\
\hline 10 & September 2021 & 4,20 \\
\hline 11 & Oktober 2021 & 4,20 \\
\hline 12 & November 2021 & 4,22 \\
\hline 13 & Desember 2021 & 4,25 \\
\hline
\end{tabular}

\section{KESIMPULAN}

Hasil perhitungan peramalan Suku Bunga Acuan (BI-7 Day Repo Rate) menggunakan metode fuzzy time series orde 15 pada bulan Desember 2020 - Desember 2021 disajikan dalam Tabel 13. Tingkat akurasi metode fuzzy time series orde 15 menggunakan MAPE diperoleh sebesar $1,14636957 \%$. yang artinya metode ini sangat baik untuk meramalkan Suku Bunga Acuan (BI-7 Day Repo Rate).

\section{DAFTAR PUSTAKA}

[1]. Anggraeini, W. (2015). Prediksi Tingkat Suku Bunga Bank Indonesia (BI Rate) Berdasarkan Data Fuzzy Time Series. 2(58), 87797409.

[2]. Brata, A. S. (2016). Penerapan Fuzzy Time Series dalam Peramalan Data Seasonal. Skripsi. Fakultas Sains dan Teknologi, Universitas Islam Negeri Maulana Malik Ibrahim.

[3]. Desmonda, D., Tursina, T., \& Irwansyah, M. A. (2018). Prediksi Besaran Curah Hujan Menggunakan Metode Fuzzy Time Series. Jurnal Sistem Dan Teknologi Informasi (JUSTIN), 6(4), 141. https://doi.org/10.26418/justin.v6i4.27036

[4]. Gemilang, F. A. (2017). Prediksi Harga Pnutupan Saham Menggunkan Fuzzy Time Series. Skripsi Fakultas Sains dan Teknologi, Universitas Sanata. 4, 9-15.

[5]. Ikshsanto, H. T. (2016). Perbandingan Tingkat Akurasi Metode Automatic Clustering, Average Based, Dan Markov Chain Fuzzy Time Series Pada Nilai Tukar (Kurs) Rupiah. Skripsi. 
Fakultas Matematika dan IImu Pengetahuan Alam, Universitas Negeri Semarang. In Unnes Journal of Mathematics (Vol. 7, Issue 1). https://doi.org/10.15294/ujm.v7i1.12574

[6]. Pambudi, R. A., Setiawan, B. D., \& Wijoyo, S. H. (2018). Implementasi Fuzzy Time Series untuk Memprediksi Jumlah Kemunculan Titik Api. Jurnal Pengembangan Teknologi Informasi Dan IImu Komputer (J-PTIIK) Universitas Brawijaya, 2(11), 4767-4776.

[7]. Paramasatya, W., Ratnawati, D. E., \& Dewi, C. (2017). Peramalan Suku Bunga Acuan ( BI Rate ) Menggunakan Metode Fuzzy Time Series dengan Percentage Change Sebagai Universe of Discourse. Skripsi. Fakultas Ilmu Komputer, Universitas Brawijaya. Jurnal Pengembangan Teknologi Informasi Dan IImu Komputer (J-PTIIK) Universitas Brawijaya, 1(11), 1285-1294.

[8]. Rahayu, R. (2020). Dampak BI 7-Days Repo Rate Terhadap Abnormal Return Dan Tranding Volume Activity Perusahaan Sektor Manufaktur, Sektor Properti dan Real Estate Serta Sektor Perbankan di BEI 2016. Skripsi. Fakultas Ekonomi dan Bisnis, Universitas Jember.

[9]. Safitri, Y., Wahyuningsih, S., \& Goejantoro, R. (2018). Peramalan Dengan Metode Fuzzy Time Series Markov Chain (Studi Kasus: Harga Penutupan Saham PT . Radiant Utama Interinsco Tbk Periode Januari 2011 - Maret 2017) Forecasting with Fuzzy Time Series Markov Chain Method ( Case Study: Closing Stock Price of. 9, 51-58.

[10]. Sari, W. M., Darnius, O., \& Sembiring, P. (2018). Perbandingan Keakuratan Dari Model Tabel Distribusi Frekuensi Berkelompok Antara Metode Sturges Dan Metode Scott. Talenta Conference Series: Science and Technology (ST), 1(1), 001-009. https://doi.org/10.32734/st.v1i1.182

[11]. Udin, A. C., \& Jatipaningrum, M. T. (2020). Peramalan Inflasi Di Indonesia Menggunakan Metode Fuzzy Time Series Based Average Dan Fuzzy Time Series Saxena-Easo. Jurnal Statistika Industri Dan Komputasi, 05(2), 1-10. 